\title{
AVALIAÇÃO DA COMPOSIÇÃo QUÍMICA DE ÁGUAS DO SISTEMA GUARAPIRANGA: ESTUDO DE CASO NOS ANOS DE 2002 E 2003
}

\author{
Eduardo M. Richter* \\ Instituto de Química, Universidade Federal de Uberlândia, CP 593, 38400-902 Uberlândia - MG, Brasil \\ Adalgiza Fornaro \\ Instituto de Astronomia, Geofísica e Ciências Atmosféricas, Universidade de São Paulo, São Paulo - SP, Brasil \\ Claudimir L. do Lago e Lúcio Angnes \\ Instituto de Química, Universidade de São Paulo, São Paulo - SP, Brasil
}

Recebido em 19/6/06; aceito em 17/11/06; publicado na web em 2/7/07

\begin{abstract}
EVALUATION OF THE CHEMICAL COMPOSITION OF THE GUARAPIRANGA WATER SYSTEM: CASE STUDY (2002 and 2003). The supply of drinking water in the Metropolitan Area of São Paulo City has been a great and serious challenge in the latest years. This work demonstrates the viability of the evaluation of the degree of contamination of the water reservoirs using analytical procedures, which allow the analysis of several compounds at relatively low cost: stripping square wave voltammetry (SSWV) and capillary zone electrophoresis with contactless conductivity detection (CZE-CCD). The results of ionic composition indicated significant contamination of the Guarapiranga water system by human activities on the reservoir banks. In fact, the Guavirutuba and Itupu streams presented high concentrations of phosphate and ammonium ions. This can be directly related to misuse and unruled occupation of the soil and precarious sanitary infrastructure.
\end{abstract}

Keywords: drinking water; water contamination; heavy metals.

\section{INTRODUÇÃO}

A Região Metropolitana de São Paulo (RMSP) é o principal pólo econômico do país e uma das regiões de maior densidade demográfica do mundo (mais de 17 milhões de habitantes). Estas características favorecem a geração de problemas ambientais sérios, como a contaminação dos mananciais de abastecimento de água potável ${ }^{1-4}$ e a degradação da qualidade do $\operatorname{ar}^{5-8}$. O abastecimento de água potável para a RMSP vem enfrentando crescentes desafios nos últimos anos, sendo atualmente o consumo igual ou ligeiramente superior à capacidade de produção da região. A este quadro deve ser adicionado o fato do agravamento gradual dos problemas de poluição que oneram e dificultam o tratamento desta água. Este panorama preocupante é bastante discutido no momento, levando à reflexão e busca de soluções para o problema. A complexidade da questão não permite qualquer tipo de solução simplista, fácil ou superficial. É preciso encarar o desafio e partir para ações que garantam água potável no futuro, sem deixar de tomar medidas imediatas para minorar o problema.

Conforme a Resolução no 357 de 2005 do CONAMA ${ }^{9}$, grande número de parâmetros físico-químicos é empregado para definir o grau de potabilidade de águas de abastecimento. A CETESB (Companhia de Tecnologia de Saneamento Ambiental $)^{1}$ faz o monitoramento de muitos destes parâmetros, mas o número de eventos ainda está muito distante do ideal, sendo o principal entrave o custo de tais procedimentos, assim como o tempo gasto por análise e a geração de resíduos. Este último tema está diretamente ligado ao volume de amostras e reagentes necessários por análise, sendo objeto de estudo de vários pesquisadores ${ }^{10-12}$.

Técnicas eletroanalíticas como redissolução voltamétrica e eletroforese capilar permitem, com custo relativamente pequeno,

*e-mail: emrichter@iqufu.ufu.br o monitoramento de grande número de parâmetros em águas de forma rápida, com boa sensibilidade, precisão e baixo consumo de amostras e reagentes.

Portanto, o objetivo deste trabalho foi contribuir na avaliação do grau de contaminação de reservatórios de água, utilizando procedimentos analíticos que permitam a análise de grande número de espécies a um custo relativamente baixo. Trata-se da utilização da técnica eletroanalítica de redissolução voltamétrica por onda quadrada para monitoramento dos metais $\mathrm{Pb}^{2+}, \mathrm{Cu}^{2+}$ e $\mathrm{Hg}^{2+}$ e da técnica de eletroforese capilar (EC) com detecção condutométrica para monitoramento de $\mathrm{Cl}^{-}, \mathrm{NO}_{3}^{-}, \mathrm{SO}_{4}^{2-}, \mathrm{CH}_{3} \mathrm{COO}, \mathrm{F}^{-}, \mathrm{PO}_{4}^{3-}, \mathrm{NH}_{4}^{+}$, $\mathrm{K}^{+}, \mathrm{Na}^{+}, \mathrm{Ca}^{2+}, \mathrm{Mg}^{2+}$ e $\mathrm{Li}^{+}$. Entre estes, $\mathrm{Pb}^{2+}, \mathrm{Cu}^{2+}, \mathrm{Hg}^{2+}, \mathrm{Cl}^{-}, \mathrm{NO}_{3}$, $\mathrm{SO}_{4}^{2-}, \mathrm{F}^{-}, \mathrm{PO}_{4}^{3-}, \mathrm{NH}_{4}^{+}$e $\mathrm{Li}^{+}$possuem limites máximos estipulados pela Legislação Brasileira ${ }^{9}$.

Contribuindo para melhor compreensão deste grave quadro de saneamento básico, um breve panorama da atual rede de abastecimento de água para a RMS é apresentado a seguir, bem como os desafios a serem enfrentados nos próximos anos.

A SABESP (Companhia de Saneamento Básico do Estado de São Paulo $)^{13}$, empresa responsável pelo abastecimento de água, produz cerca de 70 mil litros de água por segundo para atender os habitantes da RMSP. Para tanto, possui oito sistemas de captação e tratamento de água relacionados a seguir, com suas respectivas capacidades de fornecimento de água: Cantareira $\left(33 \mathrm{~m}^{3} \mathrm{~s}^{-1}\right)$, Baixo Cotia $\left(1,1 \mathrm{~m}^{3} \mathrm{~s}^{-1}\right)$, Alto Cotia $\left(1,3 \mathrm{~m}^{3} \mathrm{~s}^{-1}\right)$, Guarapiranga $\left(12 \mathrm{~m}^{3} \mathrm{~s}^{-1}\right)$, Rio Grande $\left(4,2 \mathrm{~m}^{3} \mathrm{~s}^{-1}\right)$, Ribeirão da Estiva $\left(0,1 \mathrm{~m}^{3} \mathrm{~s}^{-1}\right)$, Rio Claro $\left(4 \mathrm{~m}^{3} \mathrm{~s}^{-1}\right)$ e Alto Tietê $\left(10 \mathrm{~m}^{3} \mathrm{~s}^{-1}\right)$.

Segundo estudo elaborado pela Fundação de Apoio à Universidade de São Paulo (FUSP) ${ }^{14}$ para o Comitê da Bacia do Alto Tietê, a oferta e a demanda de água para a região da grande São Paulo são praticamente as mesmas. No período 2004-2005, o sistema disponibilizou $66,2 \mathrm{~m}^{3} \mathrm{~s}^{-1}$ de água, enquanto a demanda foi superior a $68,9 \mathrm{~m}^{3} \mathrm{~s}^{-1}$, o que demonstra a exaustão dos recursos disponíveis. 
Além da preocupação com a disponibilidade de água, os riscos com a contaminação dos mananciais existentes é outro problema a ser considerado. Portanto, não basta aumentar a oferta de água; também é necessário garantir a proteção aos mananciais existentes, pois ações corretivas são sempre mais dispendiosas que as preventivas. O problema de contaminação é grave nas Represas Billings e Guarapiranga, que sofrem com o processo de eutrofização da água causada pelo crescimento populacional desordenado nas áreas de proteção. $\mathrm{O}$ processo de eutrofização pode ser definido como um aumento da quantidade de nutrientes (principalmente compostos à base de fósforo e nitrogênio) e/ou matéria orgânica em um ecossistema aquático. Este fenômeno causa crescimento excessivo de organismos aquáticos e conseqüente aumento da freqüência de problemas ecológicos e sanitários ${ }^{3}$.

A Represa Guarapiranga, região de estudo deste trabalho, foi construída entre 1906 e 1908, com o objetivo de gerar energia na usina de Parnaíba, no rio Tietê, sendo integrada ao sistema de abastecimento de água para a cidade de São Paulo em 1927. Inicialmente, contribuía com apenas $1 \mathrm{~m}^{3} \mathrm{~s}^{-1}$, mas com o passar dos anos esse quadro foi se modificando até atingir uma vazão de $10,7 \mathrm{~m}^{3} \mathrm{~s}^{-1}$, que corresponde a aproximadamente $16 \%$ do abastecimento da RMSP, sendo superado apenas pelo sistema Cantareira. Em 1996, cerca de 3,4 milhões de pessoas dependiam da Guarapiranga ${ }^{15}$. Nos dias atuais, a vazão natural da represa está em $10 \mathrm{~m}^{3} \mathrm{~s}^{-1} \mathrm{e}$ a SABESP capta atualmente cerca de $12 \mathrm{~m}^{3} \mathrm{~s}^{-1}$ para o abastecimento. Para suprir esta diferença, são bombeados do Sistema Billings (braço do Taquacetuba) $4 \mathrm{~m}^{3} \mathrm{~s}^{-1}$ para a Represa Guarapiranga, fato que, segundo ambientalistas, piora a qualidade da água deste reservatório (aumentando o teor de metais pesados e fósforo) ${ }^{16}$. Este problema, aliado aos inúmeros outros existentes nesta bacia, torna cada vez mais importante o monitoramento contínuo de diversos analitos. Apesar da importância do Sistema Guarapiranga para a população da região, um número reduzido de trabalhos podem ser localizados na literatura sobre estudos e avaliações de seu grau de poluição. Em 2000, Beyruth ${ }^{17}$ publicou um trabalho onde estudou distúrbios periódicos, gradiente trófico e características do fitoplâncton relacionados ao crescimento de ciano-bactérias na represa. Em 2001, Mozeto e colaboradores ${ }^{18}$ realizaram um estudo no qual foram monitorados o potencial redox, sulfeto, ácidos voláteis e alguns nutrientes (carbono orgânico dissolvido, nitrato, nitrito, amônio e fósforo reativo solúvel) em sedimentos coletados na represa. Rocha e Zottarelli ${ }^{19}$, em 2002, realizaram um estudo para a identificação de fungos na água e nos solos da região. Mais recentemente, em 2004, Rocha e Silva e colaboradores ${ }^{20}$ estudaram o uso de biomarcadores para análise de poluentes em águas bombeadas do Sistema Billings à Represa Guarapiranga. Este procedimento identificou a presença contínua de poluentes como hidrocarbonetos aromáticos polinucleares e bifenóis policlorados na Represa Billings e a presença esporádica destes no Córrego Parelheiros, receptor da água bombeada da Represa Billings para a Guarapiranga.

\section{PARTE EXPERIMENTAL}

\section{Pontos de amostragem}

As amostras foram coletadas no sistema Guarapiranga, localizado na região sudoeste da Grande São Paulo (23 $43^{\prime}$ sul e $46^{\circ} 32^{\prime}$ oeste) em 8 campanhas durante 2002 e 2003. Em cada campanha, a amostragem foi realizada em seis pontos do sistema, sendo um junto à barragem da represa, próximo ao local onde a SABESP faz a captação de água para posterior distribuição, e os demais em cinco de seus principais afluentes, em locais próximos ao deságüe na represa. Na Figura 1 é apresentada a localização da região em estudo na América do Sul (a), juntamente com imagem obtida via satélite da RMSP com a localização do Sistema Guarapiranga (b) e uma imagem da Represa (c) com a localização dos seis pontos de amostragem: (1) Córrego Parelheiros; (2) Rio Embu-Guaçu; (3) Rio Embu-Mirim; (4) Córrego Guavirutuba; (5) Córrego Itupu e (6) barragem da Represa, próximo ao ponto onde a SABESP coleta água, para posterior distribuição à população.
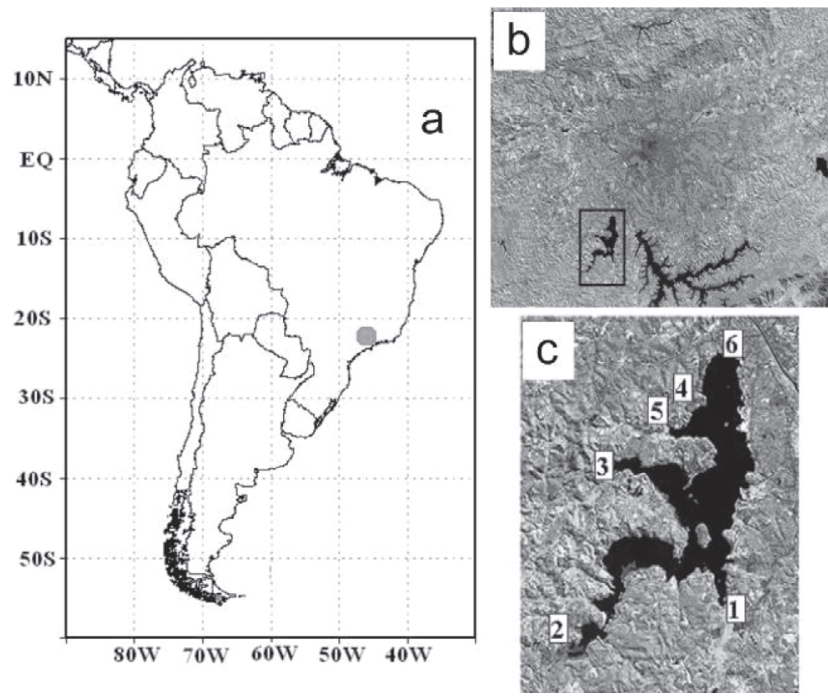

Figura 1. Localização da região de estudo: (a) América do Sul com destaque para a Região Metropolitana de São Paulo (RMSP); (b) imagem de satélite da RMSP com a localização do Sistema Guarapiranga; (c) detalhe da imagem do Sistema Guarapiranga com a indicação dos pontos de amostragem: (1) Córrego Parelheiros; (2) Rio Embu-Guaçu; (3) Rio Embu Mirim; (4) Córrego Guavirutuba; (5) Córrego Itupu; (6) barragem da Represa

\section{Procedimento para amostragem da água}

As amostras foram coletadas em frascos de polietileno de alta densidade, que passaram previamente por um rigoroso processo de limpeza. Os frascos foram inicialmente lavados com detergente e água deionizada. Em seguida, passavam um dia com uma solução de $\mathrm{HNO}_{3}-\mathrm{H}_{2} \mathrm{O}(1: 5$, v/v) e, finalmente, eram lavados e guardados com água deionizada até o momento de utilização. Além disto, estes frascos foram lavados por três vezes pela própria água no local de amostragem. A coleta realizada foi do tipo composta, ou seja, o frasco era preenchido por diferentes alíquotas coletadas em um raio de 1 a $2 \mathrm{~m}$ e cerca de $5 \mathrm{~cm}$ abaixo da superfície. As medidas de $\mathrm{pH}$ e condutividade foram realizadas no local da amostragem.

Durante 2002, quando somente os metais $\left(\mathrm{Pb}^{2+}, \mathrm{Cu}^{2+}\right.$ e $\left.\mathrm{Hg}^{2+}\right)$ foram monitorados nestas amostras, nas alíquotas para análise a posteriori, adicionava-se $\mathrm{HNO}_{3}$ no ato da coleta para que a concentração final de ácido fosse de $0,02 \mathrm{~mol} \mathrm{~L}^{-1}$. Durante a coleta, as amostras foram mantidas dentro de caixa de isopor com gelo e imediatamente após a chegada ao laboratório eram colocadas em geladeira $\left(4^{\circ} \mathrm{C}\right)$ até o momento do pré-tratamento, que antecede a análise. A partir de abril de 2003, também foram iniciadas as análises dos cátions $\left(\mathrm{NH}_{4}^{+}, \mathrm{Na}^{+}, \mathrm{K}^{+}, \mathrm{Li}^{+}, \mathrm{Ca}^{2+}\right.$ e $\left.\mathrm{Mg}^{2+}\right)$ e ânions $\left(\mathrm{Cl}, \mathrm{F}^{-}, \mathrm{NO}_{3}^{-}\right.$, $\mathrm{SO}_{4}^{2-}, \mathrm{PO}_{4}^{3-} \mathrm{e} \mathrm{CH}_{3} \mathrm{COO}^{-}$) por eletroforese capilar. Nesta etapa, o processo de amostragem foi modificado, congelando-se in loco as amostras com auxílio de gelo seco e sem adição de ácido nítrico, o que seria uma condição incompatível para os estudos envolvendo eletroforese capilar. No laboratório, as amostras foram mantidas em freezer $\left(-18^{\circ} \mathrm{C}\right)$ até momentos antes da análise. 


\section{Pré-tratamento das amostras}

$\mathrm{Na}$ análise dos metais por redissolução voltamétrica por onda quadrada, há a necessidade da remoção da matéria orgânica presente, para evitar o envenenamento do eletrodo de ouro utilizado nas análises. Este pré-tratamento foi realizado com a adição de 0,2 $\mathrm{mL}$ de ácido nítrico $3 \mathrm{~mol} \mathrm{~L}^{-1}$ à cada alíquota da amostra $(2,8 \mathrm{~mL})$ e aquecimento em banho-maria (sob ebulição) durante $1 \mathrm{~h}$, empregando-se frascos de polipropileno descartáveis. Este procedimento de pré-tratamento de amostras de água gerou percentuais de recuperação próximos a $100 \%$ para os metais monitorados neste trabalho, conforme artigo recentemente publicado ${ }^{21}$. Para a análise de íons por eletroforese capilar, as amostras foram filtradas com membrana com porosidade de $0,22 \mu \mathrm{m}$ (Millipore), instantes antes da análise.

\section{Soluções e reagentes}

Na dissolução e diluição dos reagentes e amostras utilizou-se água duplamente filtrada, destilada em destilador de quartzo e, a seguir, deionizada em sistema NANOpure da Barnstead (resistividade $>18 \mathrm{M} \Omega \mathrm{cm}$ ). As soluções padrões dos metais pesados analisados (chumbo, cobre e mercúrio) foram preparadas a partir de diluições de soluções estoque de $1000 \mathrm{mg} \mathrm{L}^{-1}$ (Merck ou Sigma-Aldrich). Os reagentes (ácido nítrico e cloreto de sódio) adicionados às amostras de água para digestão da matéria orgânica ou como eletrólito para análise de traços eram de alta pureza (Suprapur-Merck). As demais substâncias utilizadas, como analitos ou como eletrólito, foram preparadas a partir de sais de grau analítico (Merck ou Sigma-Aldrich).

\section{Instrumentação}

As medidas de $\mathrm{pH}$ e de condutividade foram realizadas no ato da amostragem de água do Sistema Guarapiranga, utilizando-se medidor de $\mathrm{pH}$ Corning (modelo $\mathrm{pH}-15$ ) e condutivímetro ColeParmer (modelo TDSTest 20), respectivamente. Um potenciostato/ galvanostato da Eco Chemie B.V. (modelo Autolab PGSTAT 20) foi utilizado para determinação dos metais (chumbo, cobre e mercúrio). Usaram-se eletrodos de ouro ${ }^{22-27}$ e voltametria de redissolução por onda quadrada com tempo de deposição de $300 \mathrm{~s}$ e o método de adições de padrão para quantificação dos metais em nível de traços. Como eletrólito suporte, além do ácido nítrico usado no prétratamento $\left(0,2 \mathrm{~mol} \mathrm{~L}^{-1}\right)$, cloreto de sódio foi adicionado às amostras para obtenção de uma concentração final de $0,015 \mathrm{~mol} \mathrm{~L}^{-1}$. A adição de cloreto, além de melhorar a sensibilidade para a análise dos metais monitorados, favorece a etapa de limpeza $(0,65 \mathrm{~V}$ por 20 s, sob agitação) do eletrodo de ouro usado na análise. Usou-se um volume de $0,6 \mathrm{~mL}$ de amostra por análise ${ }^{25}$.

Nas análises por eletroforese capilar com detecção condutométrica sem contato, foi utilizado um equipamento construído no próprio laboratório ${ }^{28,29}$, com capilar de sílica fundida de $75 \mu \mathrm{m}$ de d.i. e $40 \mathrm{~cm}$ de comprimento efetivo (até o detector). As injeções das amostras, para análise de cátions e ânions, foram realizadas aplicando-se pressão positiva ao reservatório contendo a amostra (injeção hidrodinâmica). Para análise de ânions ${ }^{30,31}$, dois tampões de corrida foram utilizados. Para analisar $\mathrm{Cl}^{-}, \mathrm{NO}_{3}^{-}, \mathrm{SO}_{4}{ }^{2-} \mathrm{e} \mathrm{CH}_{3} \mathrm{COO}$ usou-se o tampão composto por ácido 2-[N-morfolino]etanosulfônico e L-histidina (MES/His) $20 \mathrm{mmol} \mathrm{L}^{-1}$ (pH 6,0) e inversor de fluxo hidróxido de N-cetil-N-N-N-trimetilamônio (CTAH) 0,16 mmol L-1. Para as análises de $\mathrm{F}^{-}$e $\mathrm{PO}_{4}^{3-}$ usou-se o tampão ácido lático $10 \mathrm{mmol} \mathrm{L}^{-1} / \mathrm{L}$-histidina $2,5 \mathrm{mmol} \mathrm{L}^{-1}(\mathrm{pH} \mathrm{3,7)} \mathrm{e} \mathrm{CTAH}$ $0,32 \mathrm{mmol} \mathrm{L}^{-1}$. Nestes estudos, foram utilizados aspartato e succinato, respectivamente, como padrões internos para análise de

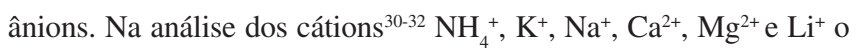
tampão de corrida era composto por ácido lático/His $20 \mathrm{mmol} \mathrm{L}^{-1}$, éter 18-coroa-6 2,5 mmol L-1 e metanol (5\%, v/v), $\mathrm{pH} 4,9$. Nestes estudos, o padrão interno utilizado foi trietanolamina. A quantificação dos íons por EC foi realizada mediante uso de curva analítica, sendo que o padrão interno foi usado para compensar eventuais flutuações do método.

\section{RESULTADOS E DISCUSSÃO}

Durante 2002 e 2003, foram coletadas 48 amostras de água no Sistema Guarapiranga em 8 campanhas diferentes: 4 em 2002 (14/ 05, 26/07, 05/09 e 19/11) e 4 em 2003 (28/02, 30/04, 29/07 e 08/ 10). Em cada campanha realizaram-se amostragens em 6 pontos diferentes do sistema, sendo que cinco pontos localizavam-se em afluentes próximos ao deságüe na represa e um ponto próximo ao local onde a SABESP retira água para o abastecimento humano em São Paulo (Figura 1c).

Devido a algumas das espécies estudadas serem de importância ambiental e, portanto, existir legislação ${ }^{9}$ determinando os teores máximos permitidos, é interessante comparar estes valores com os respectivos valores do limite de detecção das técnicas utilizadas (Tabela 1).

Tabela 1. Comparação entre os valores máximos de concentração estipulados pela Legislação Brasileira ${ }^{9}$ de algumas das espécies importantes na avaliação do padrão de qualidade de águas de classe 1 e os valores de limite de detecção (calculados a partir do valor médio da linha base multiplicada por três) dos métodos aplicados no presente estudo

\begin{tabular}{lccc}
\hline Ín & $\begin{array}{c}\text { Legislação* } \\
\mathrm{mg} \mathrm{L}^{-1}\end{array}$ & \multicolumn{2}{c}{ Limite de deteção } \\
$\mathrm{mg} \mathrm{L}^{-1}$ & $\mu \mathrm{mol} \mathrm{L}$ \\
\hline $\mathrm{Cl}^{-}$ & 250 & 0,23 & 6,5 \\
$\mathrm{NO}_{3}^{-}$ & 10 & 0,43 & 7,2 \\
$\mathrm{SO}_{4}^{2-}$ & 250 & 0,50 & 5,2 \\
$\mathrm{CH}_{3} \mathrm{COO}^{-}$ & - & 4,26 & 72,2 \\
$\mathrm{~F}^{-}$ & 1,4 & 0,75 & 39,5 \\
$\mathrm{PO}_{4}^{3-}$ & 0,15 & 1,00 & 10,5 \\
$\mathrm{NH}_{4}^{+}$ & 2,2 & 0,09 & 5,0 \\
$\mathrm{~K}^{+}$ & - & 0,18 & 4,6 \\
$\mathrm{Na}^{+}$ & - & 0,19 & 8,3 \\
$\mathrm{Ca}^{2+}$ & - & 0,20 & 5,0 \\
$\mathrm{Mg}^{2+}$ & - & 0,19 & 7,8 \\
$\mathrm{Li}^{+}$ & 2,5 & 0,23 & 33,3 \\
\hline & $(\mu \mathrm{g} \mathrm{L}$ & $(\mu \mathrm{g} \mathrm{L})$ & $(\mathrm{nmol} \mathrm{L})$ \\
\hline $\mathrm{Pb}^{2+}$ & 10 & 0,08 & 0,39 \\
$\mathrm{Cu}^{2+}$ & 9 & 0,09 & 1,42 \\
$\mathrm{Hg}^{2+}$ & 0,2 & 0,10 & 0,50 \\
\hline
\end{tabular}

* Valores máximos permitidos para potabilidade de águas (Resolução CONAMA 357/2005).

Fica demonstrado que, em relação à eletroforese capilar, apenas para o íon fosfato, o limite de detecção está bem acima do valor máximo permitido pela legislação. Já para os metais chumbo, cobre e mercúrio, os limites de detecção obtidos por voltametria de redissolução estão abaixo dos valores máximos aceitos, o que torna esta técnica bastante atraente para esta aplicação.

Na Tabela 2, são apresentados os valores mínimos, máximos e a média das concentrações para cada parâmetro analisado nos 6 diferentes pontos de coleta no Sistema Guarapiranga. Fluoreto, lítio 
Tabela 2. Resultados obtidos para os parâmetros monitorados no Sistema Guarapiranga: 1-Córrego Parelheiros; 2-Rio Embu-Guaçu; 3-Rio Embu-Mirim; 4- Córrego Guavirutuba; 5-Córrego Itupu; 6- barragem da Represa

\begin{tabular}{|c|c|c|c|c|c|c|c|c|c|c|c|c|}
\hline \multirow[b]{3}{*}{ Parâmetros } & \multicolumn{12}{|c|}{ Pontos de amostragem } \\
\hline & \multicolumn{2}{|c|}{1} & \multicolumn{2}{|c|}{2} & \multicolumn{2}{|c|}{3} & \multicolumn{2}{|c|}{4} & \multicolumn{2}{|c|}{5} & \multicolumn{2}{|c|}{6} \\
\hline & MM & M & MM & M & MM & M & MM & M & MM & M & MM & M \\
\hline $\mathrm{pH}$ & 6,0 a 8,4 & 7,6 & 6,0 a 6,7 & 6,4 & 6,7 a 7,1 & 7,0 & 7,1 a 7,5 & 7,3 & 7,2 a 7,5 & 7,4 & 7,5 a 8,6 & 8,1 \\
\hline Cond. & 175 a 206 & 189 & 35 a 43 & 39 & 180 a 253 & 212 & 558 a 609 & 576 & 450 a 536 & 500 & 120 a 142 & 136 \\
\hline $\mathrm{Pb}^{2+}$ & $<\mathrm{LD}$ a 2,3 & 0,9 & $<\mathrm{LD}$ a 2,7 & 1,0 & $<\mathrm{LD}$ a 2,0 & 0,8 & $<\mathrm{LD}$ a 2,7 & 1,7 & $<\operatorname{LD}$ a 7,0 & 3,2 & $<\mathrm{LD}$ a 1,0 & 0,2 \\
\hline $\mathrm{Cu}^{2+}$ & 0,35 a 12,3 & 4,2 & 0,9 a 5,8 & 3,0 & $<\operatorname{LD}$ a 16,3 & 3,3 & 3,5 a 16,7 & 7,2 & 1,6 a 11,1 & 6,3 & 13,8 a 37,6 & 22,6 \\
\hline $\mathrm{Cl}^{-}$ & 24,4 a 28,5 & 25,9 & 3,8 a 6,2 & 5,0 & 16,2 a 23,0 & 20,7 & 49,8 a 53,7 & 51,4 & 42,9 а 46,9 & 44,9 & 12,5 a 23,2 & 17,3 \\
\hline $\mathrm{SO}_{4}^{2-}$ & 10,4 a 13,1 & 12,2 & 1,2 a 1,4 & 1,3 & 4,9 a 7,9 & 6,5 & 24,4 a 28,8 & 26,5 & 18,4 a 25,1 & 22,3 & 6,3 a 8,2 & 7,2 \\
\hline $\mathrm{NO}_{3}^{-}$ & $0,1 \mathrm{a} 1,7$ & 0,8 & 0,7 a 1,4 & 1,1 & 0,4 a 2,6 & 1,1 & $<\mathrm{LD}$ & $<\mathrm{LD}$ & $<\mathrm{LD}$ & $<\mathrm{LD}$ & 1,5 a 3,3 & 2,7 \\
\hline $\mathrm{CH}_{3} \mathrm{COO}^{-}$ & $<\mathrm{LD}$ & $<\mathrm{LD}$ & $<\mathrm{LD}$ & $<\mathrm{LD}$ & $<\mathrm{LD}$ & $<\mathrm{LD}$ & 11,8 a 16,6 & 10,9 & 6,0 a 16,1 & 11,9 & $<\mathrm{LD}$ & $<\mathrm{LD}$ \\
\hline $\mathrm{PO}_{4}^{3-}$ & $<\mathrm{LD}$ & $<\mathrm{LD}$ & $<\mathrm{LD}$ & $<\mathrm{LD}$ & $<\mathrm{LD}$ & $<\mathrm{LD}$ & 6,1 a 9,7 & 7,9 & 5,0 a 5,5 & 5,3 & $<\mathrm{LD}$ & $<\mathrm{LD}$ \\
\hline $\mathrm{NH}_{4}^{+}$ & 0,5 a 0,9 & 0,7 & 0,3 a 0,5 & 0,4 & 3,4 a 12,3 & 7,5 & 29,7 a 37,7 & 33,8 & 22,2 a 32,1 & 27,7 & $<\mathrm{LD}$ a 0,6 & 0,3 \\
\hline $\mathrm{K}^{+}$ & 5,5 a 5,7 & 5,6 & 0,4 a 2,11 & 1,3 & 4,6 a 6,9 & 5,6 & 10,9 a 14,1 & 12,1 & 9,1 a 14,5 & 11,0 & 3,7 a 6,1 & 5,1 \\
\hline $\mathrm{Na}^{+}$ & 18,8 a 21,9 & 20,5 & 2,3 a 5,9 & 4,1 & 16,2 a 28,7 & 20,1 & 39,6 a 60,7 & 47,4 & 34,2 a 52,3 & 40,8 & 14,3 a 24,1 & 17,7 \\
\hline $\mathrm{Ca}^{2+}$ & 8,3 a 15,8 & 11,6 & 1,4 a 2,1 & 1,8 & 7,5 a 10,6 & 8,8 & 13,3 a 20,2 & 16,7 & 9,3 a 21,1 & 13,9 & 7,7 a 9,4 & 8,7 \\
\hline $\mathrm{Mg}^{2+}$ & 1,6 a 2,1 & 1,9 & 0,5 a 0,9 & 0,7 & 1,6 a 2,1 & 1,9 & 3,0 a 4,3 & 3,5 & 2,8 a 3,3 & 3,0 & 1,5 a 1,9 & 1,7 \\
\hline
\end{tabular}

MM: Concentração mínima e máxima; M: média; LD: limite de detecção. Unidades: Cond. $\left(\mu \mathrm{Sm}^{-1}\right)$; $\mathrm{Pb}^{2+}, \mathrm{Cu}^{2+}\left(\mu \mathrm{g} \mathrm{L}^{-1}\right)$; demais íons $(\mathrm{mg}$ $\left.\mathrm{L}^{-1}\right) .\left(\left[\mathrm{Hg}^{2+}\right],\left[\mathrm{F}^{-}\right],\left[\mathrm{Li}^{+}\right]\right)<\mathrm{LD}$ para todas as amostras.

e mercúrio, em todos os pontos de amostragem, assim como nos diferentes períodos de coleta, apresentaram concentrações abaixo do limite de detecção (Tabelas 1 e 2).

Analisando-se os resultados da Tabela 2 em relação aos valores máximos permitidos (Tabela 1), observou-se que os córregos Guavirutuba e Itupu apresentaram problemas graves de contaminação por fosfato e amônio, com concentrações muito superiores ao máximo estabelecido pela Legislação Brasileira ${ }^{9}$. Este tipo de poluição é um reflexo direto de problemas crônicos existentes nas margens destes córregos, dentre os quais a alta densidade demográfica e falta de saneamento básico, assim como a existência de grande número de moradias irregulares. Destaca-se que a amônia é uma substância tóxica restritiva à vida dos peixes e as concentrações médias de amônio (33,8 e 27,7 mg L ${ }^{-1}$ nos córregos Guavirutuba e Itupu, respectivamente) situam-se muito acima dos $5 \mathrm{mg} \mathrm{L}^{-1}$, que é o limite máximo suportado por muitas espécies ${ }^{1}$.

Em relação aos demais íons, todos estavam presentes em concentrações mais elevadas nestes dois córregos, com exceção do nitrato. Este ânion, porém, apresentou concentrações significativas junto à barragem da Represa. Trata-se, neste caso, do provável produto de oxidação biológica do nitrogênio amoniacal e/ou orgânico ${ }^{1}$ proveniente da água dos córregos Guavirutuba e Itupu, locais onde as concentrações do íon amônio foram elevadas.

Outro problema identificado foi a concentração de cobre presente nas amostras de água coletadas junto à barragem da Represa, ligeiramente superior ao máximo estabelecido pela Legislação Brasileira $^{9}\left(9 \mu \mathrm{g} \mathrm{L}^{-1}\right)$ em todas as coletas realizadas. Os resultados da análise das demais amostras revelaram que o cobre não vem dos córregos e rios que abastecem a Represa, mas provavelmente sua origem está na adição de sais de cobre, realizada para evitar a proliferação das algas. A propagação das algas, por sua vez, está diretamente ligada ao nível de nutrientes (fosfato, principalmente) despejados nas águas pela população que habita o entorno da bacia. Cabe destacar que em estudo anterior constatou-se baixíssimo nível de cobre na água de abastecimento do Instituto de Química da $\mathrm{USP}^{24}$, o que sugere que grande parte deste metal é retido no processo de tratamento de águas da SABESP.

O ânion acetato está presente em níveis consideráveis nos córregos Itupu e Guavirutuba. Porém, nas amostras coletadas junto à barragem da Represa, esta espécie não foi detectada. Isto se deve a dois prováveis fenômenos: diluição, pois os outros afluentes não apresentavam níveis detectáveis desta espécie e, consumo ou transformação em espécies secundárias pela ação de bactérias.

Os íons chumbo, mercúrio, lítio, fluoreto, cloreto e sulfato estavam presentes em níveis bem inferiores aos máximos estabelecidos pela Legislação Brasileira para águas destinadas ao consumo humano do tipo classe 1 . Os íons potássio, sódio, cálcio e magnésio também se encontravam em concentrações consideradas dentro do padrão para este tipo de água.

Em relação às medidas de condutividade, tanto as amostras coletadas junto à barragem da Represa, como nos demais afluentes, com exceção feita ao Rio Embu-Guaçu (condutividade $\approx 40$ $\mu \Omega \mathrm{cm}^{-1}$ ), são considerados ambientes impactados (condutividade acima de $\left.100 \mu \Omega \mathrm{cm}^{-1}\right)^{1}$. Em relação às medidas de $\mathrm{pH}$, quase a totalidade das amostras se situaram dentro do intervalo entre 6,5 a 8,5, faixa de $\mathrm{pH}$ considerada aceitável, segundo o Ministério da Saúde ${ }^{33}$. Exceção foi observada em algumas coletas no Rio EmbuGuaçu onde foram registrados valores de $\mathrm{pH}$ inferiores a 6,5 para metade das coletas realizadas. Porém, na Resolução CONAMA $357 / 2005^{9}$, o padrão de qualidade de águas deve apresentar valor de $\mathrm{pH}$ entre 6 e 9. Assim, em relação a este parâmetro, os valores estão dentro dos aceitáveis.

A Figura 2 apresenta a comparação entre os valores de condutividade medidos $\left(\mathrm{k}_{\text {med }}\right)$ e calculados $\left(\mathrm{k}_{\text {cal }}\right)$ a partir das concentrações das espécies iônicas analisadas em cada amostra coletada a partir de abril de 2003. Como pode ser observado, o valor obtido para a condutividade calculada foi muito próximo e sempre menor que o valor da condutividade medida. Este resultado indica a presença de espécies iônicas não analisadas e que contribuem para o teor iônico destas águas, dentre os quais íons carbonato e bicarbonato. Portanto, pode-se considerar que as espécies iônicas majoritárias presentes nas amostras foram analisadas em sua quase totalidade.

Apesar das concentrações de chumbo estarem situadas bem abaixo do valor máximo permitido, é interessante observar sua variabilidade ao longo do período estudado em três diferentes pontos de amostragem: Guavirutuba, Embu-Guaçu e Itupu (Figura 3). 


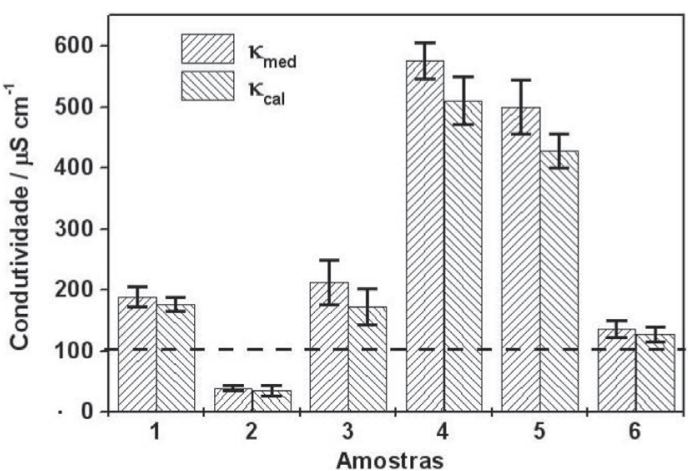

Figura 2. Comparação entre os valores de condutividade medidos $\left(k_{\text {med }}\right)$ e calculados $\left(k_{\text {cal }}\right)$ para a média dos valores quantificados em cada ponto de coleta. A linha em $100 \mu \mathrm{S} \mathrm{cm}^{-1}$, marca o valor máximo da condutividade para águas consideradas não impactadas ${ }^{l}$

As mais altas concentrações de chumbo foram observadas no Córrego Itupu, sendo que para a amostragem do dia 19/11/2002, o teor de chumbo atingiu 7,0 $( \pm 1,6) \mu \mathrm{g} \mathrm{\textrm {L } ^ { - 1 }}$. Porém, esta concentração está próxima ao valor de $10 \mu \mathrm{g} \mathrm{L}^{-1}$, limite de chumbo considerando o padrão de potabilidade de águas ${ }^{1}$. É importante observar que os dados obtidos pela CETESB para chumbo pelo monitoramento realizado neste período foram todos abaixo do limite de detecção $\left(100 \mu \mathrm{g} \mathrm{L}^{-1}\right)$, valor 10 vezes maior do que o máximo permitido pela Legislação Brasileira atual $\left(10 \mu \mathrm{g} \mathrm{L}^{-1}\right)^{9}$.

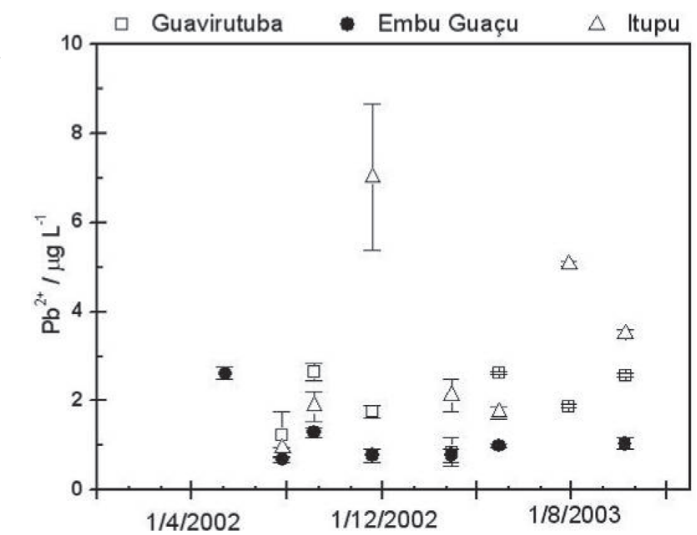

Figura 3. Variabilidade da concentração de $\mathrm{Pb}^{2+}$ ao longo do período estudado em três diferentes pontos de amostragem. A barra de erros indica a estimativa do desvio padrão da análise em triplicata da respectiva amostra

Eventos de chuva podem causar possíveis interferências na variabilidade das concentrações de espécies químicas presentes em águas de superfície, seja por diluição ou contribuição por enriquecimento via escoamento de solos. Para a região em estudo, a partir da Figura 4 observam-se períodos secos (maio, junho e julho) e chuvosos (dezembro, janeiro e fevereiro) bem definidos. Pode ser observado também o perfil da pluviometria mensal dos anos de 2002 e 2003 comparados com a pluviometria mensal média de 70 anos, destacando-se os meses de novembro de 2002 e janeiro de 2003, que apresentaram pluviometria significativamente acima da média. Porém, não foi possível observar influência significativa desse perfil de chuvas na variabilidade das concentrações das espécies no período estudado, por exemplo, para chumbo e cobre (Figuras 3 e 5) e o valor de $\mathrm{pH}$ (Figura 6).

As Figuras 5 e 6 apresentam resultados do presente estudo juntamente com dados da CETESB disponibilizados nos Relatórios de Qualidade das Águas Interiores do Estado de São Paulo 2002 e $2003^{1}$ para cobre e valores de $\mathrm{pH}$. Na Figura 5, compara-se a vari-

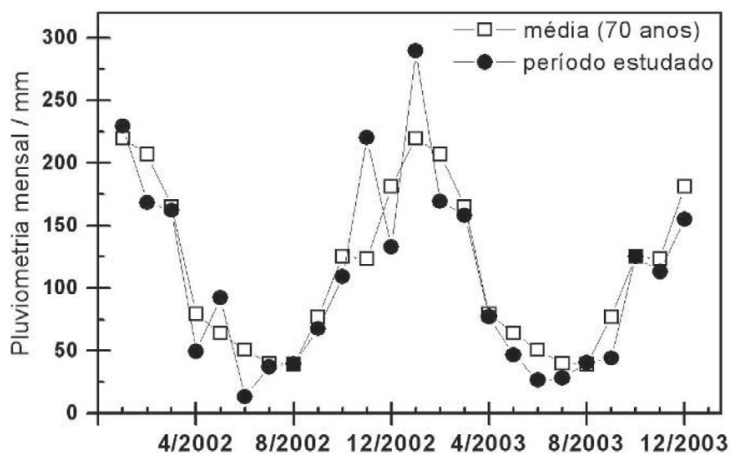

Figura 4. Pluviometria mensal a partir de dados da Estação Meteorológica do Instituto de Astronomia, Geofísica e Ciências Atmosféricas (IAG/USP) localizada no Parque Estadual Fontes do Ipiranga (23 $39^{\prime}$ sul e 46 $37^{\circ}$ oeste)

abilidade anual de cobre na barragem da Represa Guarapiranga, um dos pontos de monitoramento da CETESB, que coincide com um dos locais de amostragem do presente estudo. Porém, as datas de amostragem não foram coincidentes, sendo que os dias mais próximos foram 13 e 14/05/2002, amostrados respectivamente, pela CETESB e por este trabalho. Nestas duas avaliações as concentrações de cobre foram muito próximas. O mesmo aconteceu para os pares de amostragem de 30/04 e 08/05/2003 e de 17 e 29/07/2003. De forma geral, é evidente a variabilidade significativa das concentrações de cobre, tanto entre os dois diferentes estudos, como ao longo do ano. Destaca-se o fato de que a concentração máxima de $9 \mu \mathrm{g} \mathrm{\textrm {L } ^ { - 1 }}$ foi ultrapassada por praticamente todas as amostras de ambos os estudos.

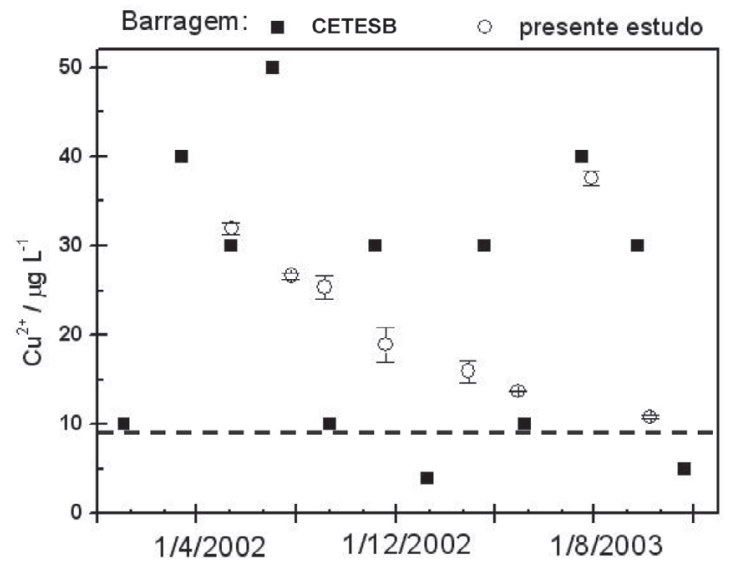

Figura 5. Comparação entre as concentrações de cobre avaliadas pela CETESB $^{1}$ e no presente estudo, em amostras de águas da Represa Guarapiranga coletadas na barragem. A linha pontilhada em $9 \mu \mathrm{g} L^{-1}$, marca o valor máximo da concentração de cobre permitida em águas para abastecimento pela Legislação Brasileira ${ }^{1,9}$

A Figura 6 apresenta a comparação entre os valores de $\mathrm{pH}$ determinados pela CETESB e pelo presente estudo, para amostras da barragem e do Córrego Embu-Guaçu. Estes dois pontos de amostragem, praticamente, representaram situações opostas em relação à qualidade de suas águas. No Córrego Embu-Guaçu, praticamente todos os parâmetros avaliados foram mais baixos que os do ponto da barragem, com exceção do chumbo.

\section{CONCLUSÃO}

O conjunto formado pelas técnicas de redissolução voltamétrica por onda quadrada e eletroforese capilar mostrou-se bastante ade- 


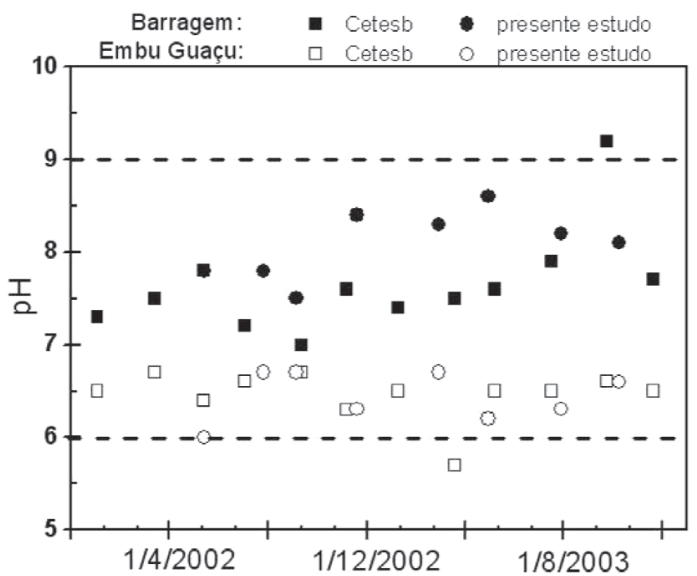

Figura 6. Comparação entre os valores de $\mathrm{pH}$ medidos pela CETESB ${ }^{l}$ e no presente estudo, em amostras de águas coletadas na barragem da Represa Guarapiranga e no Rio Embu-Guaçu. As linhas tracejadas entre pH 6 e 9 indicam a faixa de $\mathrm{pH}$ permitida em águas para abastecimento pela Legislação Brasileira ${ }^{9}$

quado para a determinação das espécies estudadas, com exceção do íon fosfato, para qual o limite de detecção deveria ser reduzido por um fator de 10 para atender à legislação vigente. Para os demais íons estudados, os limites de detecção foram da ordem de 2 vezes menor (no caso do fluoreto) a mais de 1000 vezes (para cloreto) quando comparados com os valores estabelecidos pela Legislação. Dentre as vantagens das técnicas exploradas neste estudo destaca-se a possibilidade de quantificar múltiplas espécies em um mesmo experimento, de forma rápida, precisa e com elevada sensibilidade. A utilização de instrumentação simples, de custo reduzido e que requer pouca manutenção torna o conjunto atraente. A possibilidade de miniaturização do sistema, sua portabilidade e a sua complementaridade também são aspectos a serem considerados.

Os resultados da avaliação da composição iônica de amostras de águas do Sistema Guarapiranga indicaram contaminação significativa de suas águas, promovida por atividades antrópicas no entorno da represa. De fato, nos Córregos Guavirutuba e Itupu, os íons fosfato e amônio apresentaram concentrações acima dos máximos permitidos pela Legislação, o que pode estar diretamente relacionado às características de uso e ocupação do solo com precária infra-estrutura sanitária. $\mathrm{O}$ cobre esteve presente em concentrações acima do máximo estabelecido somente junto à barragem da Represa, provavelmente devido à adição de sais deste metal para controle da proliferação de algas. $\mathrm{O}$ chumbo apresentou resultados preocupantes, pois apesar de estar presente em concentrações abaixo do permitido pela Legislação, foi determinado nos diferentes pontos de amostragem, destacando-se que esse metal pesado pode resultar em efeitos negativos ao ecossistema a longo prazo, devido à bioacumulação, tanto na flora, como na fauna aquática. Finalmente, pode-se afirmar que a continuidade do crescimento demográfico nas margens desta represa e a inércia do poder público no sentido de controlar a situação permitem facilmente prever o agravamento das condições das águas deste importante manancial de abastecimento.

\section{AGRADECIMENTOS}

Este estudo foi desenvolvido com o apoio financeiro da FAPESP e CNPq. E. M. Richter agradece a bolsa de doutoramento recebida da FAPESP (Processo 00/10384-0).

\section{REFERÊNCIAS}

1. http://www.cetesb.sp.gov.br/Agua/rios/relatorios.asp, acessada em Maio 2006.

2. http://www.sabesp.com.br, acessada em Maio 2006.

3. Branco, S. M.; Hidrologia Aplicada à Engenharia Sanitária, $3^{\mathrm{a}}$ ed., CETESB: São Paulo, 1986

4. Martos, H. L.; Maia N. B.; Indicadores Ambientais, Shell do Brasil S.A.: Sorocaba, 1997.

5. CETESB; Relatório de Qualidade do Ar no Estado de São Paulo - 2004, http://www.cetesb.sp.gov.br, acessada em Maio 2006.

6. Finlayson-Pitts, B. J.; Pitts Jr., J. N.; Atmospheric Chemistry: Fundamentals and Experimental Techniques, Ed. John Wiley \& Sons: New York, 1986.

7. Seinfeld, J. H.; Pandis, S. N.; Atmospheric Chemistry and Physics of Air Pollution, Ed. John Wiley: New York, 1998.

8. Godish, T.; Air Quality, $3^{\text {rd }}$ ed., Ed. Lewis Publishers: Boca Raton, 1997.

9. Resolução No 357 - Conselho Nacional do Meio Ambiente - CONAMA, 17 de março de 2005.

10. Rocha, F. R. P.; Nóbrega, J. A.; Fatibello, O.; Green Chem. 2001, 3, 216.

11. Prado, A. G. S.; Quim. Nova 2003, 26, 738.

12. da Silva, F. M.; de Lacerda, P. S. B.; Jones Jr., J.; Quim. Nova 2005, 28, 103.

13. http://www.SABESP.com.br/o_que_fazemos/captacao_e_distribuicao _de_agua/sistemas_metropolitano2.htm, acessada em Maio 2006.

14. http://www.fusp.org.br, acessada em Maio 2006.

15. Instituto Socioambiental (ISA); Diagnóstico Socioambiental Participativo Preliminar da Bacia Hidrográfica do Guarapiranga - Projeto Ecoscambio, 1996.

16. www.prefeitura.sp.gov.br/secretarias/meio_ambiente/bacias/ ABASTECIMENTO_DE_AGUA.rtf, acessada em Maio 2006.

17. Beyruth, Z.; Hydrobiologia 2000, 424, 51 .

18. Mozeto, A. A.; Silvério, P. F.; Soares, A.; Sci. Total Environ. 2001, 266, 135.

19. da Rocha, M.; Zottarelli, C. L. A. P.; Acta Bot. Bras. 2002, 16, 287.

20. Rocha e Silva, T. A. A.; Rantin, F. T.; Matsumura-Tundisi, J. E.; Matsumura-Tundisi, T.; Tundisi, J. G.; Degterev, I. A.; Ecotoxicol. Environ. Saf. 2004, 59, 109.

21. Richter, E. M.; do Lago, C. L.; Angnes, L.; Quim. Nova 2006, 29, 862.

22. Angnes, L.; Richter, E. M.; Kume, G. H.; Augelli, M. A.; Anal. Chem. 2000, 72,5503 .

23. Richter, E. M.; Augelli, M. A.; Kume, G. H.; Mioshi, R. N.; Angnes, L.; Fresenius J. Anal. Chem. 2000, 366, 444.

24. Richter, E. M.; Magarotto, S.; Augelli, M. A.; Angnes, L.; Electroanalysis 2001, 13,760 .

25. Richter, E. M.; Pedrotti, J. J.; Angnes, L.; Electroanalysis 2003, 15, 1871.

26. Augelli, M. A.; Munoz, R. A. A.; Richter, E. M.; Gouveia, A.; Angnes, L.; Electroanalysis 2005, 17, 755.

27. Augelli, M. A.; Munoz, R. A. A.; Richter, E. M.; Cantagallo, M. I.; Angnes, L.; Food Chem. 2007, 101, 579.

28. da Silva, J. A. F.; do Lago, C. L.; Anal. Chem. 1998, 70, 4339.

29. da Silva, J. A. F.; Guzman, N.; do Lago, C. L.; J. Chromatogr., A 2002, 942 , 249.

30. Munoz, R. A. A.; Richter, E. M.; de Jesus, D. P.; do Lago, C. L.; Angnes, L.; J. Braz. Chem. Soc. 2004, 15, 523.

31. Richter, E. M.; de Jesus, D. P.; Munoz, R. A. A.; do Lago, C. L.; Angnes, L.; J. Braz. Chem. Soc. 2005, 16, 1134.

32. da Silva, J. A. F.; Ricelli, N. L.; Carvalho, A. Z.; do Lago, C. L.; J. Braz. Chem. Soc. 2003, 14, 265

33. Ministério da Saúde, Portaria No 518, de 25 de março de 2004. 